\title{
Beat 'em or Join 'em? Export Subsidies versus International Research Joint Ventures in Oligopolistic Markets*
}

\author{
J. Peter Neary and Paul O'Sullivan \\ University College, Dublin 4, Ireland
}

\begin{abstract}
We compare adversarial with cooperative industrial and trade policies in a dynamic oligopoly game in which a home and foreign firm compete in R\&D and output and, because of spillovers, each firm benefits from the other's R\&D. When the government can commit to an export subsidy, such a policy raises welfare relative to cooperation, except when R\&D is highly effective and spillovers are near-complete. Without commitment, however, subsidisation may yield welfare levels much lower than cooperation and lower even than free trade, though qualifications to the dangers from no commitment are noted.
\end{abstract}

Keywords: R\&D spillovers; R\&D cooperative agreements; RJVs (research joint ventures); strategic trade policy; export subsidies

JEL classification: $F 12 ; F 13$

\section{Introduction}

Governments everywhere see international success for domestic high-technology firms as a desirable objective and measures to encourage such firms as an important component of economic policy. While this perspective suggests adopting an adversarial approach to promoting "national champions", governments are also aware of the potential benefits to home firms of cooperative arrangements such as research joint ventures with foreign firms. Finally, both domestic governments and international regulatory bodies (such as the EU Commission) are increasingly conscious of the need

\footnotetext{
*We are very grateful to Bruno Cassiman, Dermot Leahy, Ian Wooton, three anonymous referees and participants at the Irish Economic Association Annual Conference, 1996, at a CEPR Conference on Competition and Trade Policy, Barcelona, December 1997, at the Conference on Competition and Industrial Policies in Open Economies in Bergen, May 1998, and at EEA 98 in Berlin for helpful comments. Neary's work forms part of the International Economic Performance Programme of the Centre for Economic Performance, London School of Economics, supported by the UK SSRC. This research was undertaken with support from the European Union Phare ACE Programme contract no. P96-6092-R and was written while O'Sullivan was a Lecturer at National University of Ireland, Maynooth. An earlier version was circulated as CEPR Discussion Paper No. 1916.
} 
to formulate and enforce guidelines for pro-competitive behaviour at the international as well as at the national level.

Developing an analytical framework to deal with these issues poses formidable challenges. At the very least, it requires the application of a number of sub-disciplines in economics, drawing on work in the fields of industrial and trade policy, technology policy and competition policy. In this paper we take a small step in this direction by combining the insights from two strands of recent literature, the theory of strategic trade policy, associated especially with Brander and Spencer (1985), and the analysis of R\&D cooperation in oligopolistic markets pioneered by d'Aspremont and Jacquemin (1988). In particular, we try to throw light on the relative merits of adversarial and cooperative approaches. From the perspective of domestic welfare, should governments encourage home firms to adopt a "beat 'em" or a "join 'em" approach to foreign rivals?

The theory of strategic trade policy has shown that intervention in oligopolistic markets can raise domestic welfare if governments use their superior commitment powers to "shift profits" towards home firms. The limitations of the theory's interventionist thrust have been well documented: in particular, subsidies are justified when firms engage in quantity competition but not in price competition, and foreign retaliation leads to a prisoners' dilemma from which both governments are likely to lose; see Brander (1995) for references. Nevertheless it constitutes one of the few strictly economic justifications for policy activism. However, the merits of subsidising exporting firms have to be re-examined in the light of two key considerations in the recent literature. First, a number of authors have noted that the benefits of strategic intervention may be reduced if the government cannot commit in advance to its policy. Second, the benefits of adversarial policies need to be reconsidered in the light of the potential gains from cooperation between firms. While the effects of $R \& D$ cooperation in the presence of R\&D spillovers have been extensively studied in a closed-economy context, its implications in open economies have been little studied as yet. ${ }^{1}$ The contribution of this paper is to extend the analysis of international research joint ventures to allow for asymmetries between firms and to compare cooperation with free trade and export subsidisation both in general and for specific functional forms.

We do this in a canonical model which is introduced in Section II. This

\footnotetext{
${ }^{1}$ Strategic policy with imperfect government commitment has been explored by Maskin and Newbery (1990), Goldberg (1995), Karp and Perloff (1995), O’Sullivan (1995) and Leahy and Neary (1999b). Guffens (1995), Motta (1996), Muniagurria and Singh (1997), Qiu and Tao (1998) and Leahy and Neary (1999a) have studied R\&D spillovers in open economies. None of these papers considers the general asymmetric case studied here, or compares international R\&D cooperation with export subsidies within a common framework.
}

(C) The editors of the Scandinavian Journal of Economics 1999. 
abstracts from issues of domestic competition policy by assuming a duopolistic market in which a single home firm competes with a foreign rival and all output is exported. We also consider a restricted range of policies, ignoring direct subsidies to $\mathrm{R} \& \mathrm{D}$ and assuming (plausibly) that export subsidies are not provided if firms cooperate on R\&D. We look at the incentives firms face to invest in R\&D with and without $R \& D$ cooperation in Section III, and the role of export subsidies with and without government commitment in Section IV. Welfare levels between the four equilibria are compared in Section V and Section VI shows how the comparison is facilitated when special functional forms are assumed. ${ }^{2}$

\section{The Model}

We consider a two-period Cournot duopoly model, in which a home and a foreign firm export a homogeneous commodity to a third country which consumes all of the good. Period 1 is the pre-market R\&D phase and period 2 is the output phase. The home and foreign firms choose R\&D levels $x$ and $x^{*}$, respectively, in period 1 and produce output levels $q$ and $q^{*}$, respectively, in period 2. R\&D incurs up-front costs in period 1 given by $\Gamma(x)$ and $\Gamma^{*}\left(x^{*}\right)$ for the home and foreign firm, respectively. The benefits come in the form of lower marginal costs in period 2 (assumed independent of the level of output), but not all the benefits accrue to the firm which carries out the $\mathrm{R} \& \mathrm{D}$ :

$$
\begin{aligned}
c & =c\left(x, x^{*}\right), & c_{x}=-\theta, & c_{x^{*}}=-\beta \theta \\
c^{*} & =c^{*}\left(x^{*}, x\right), & c_{x^{*}}^{*}=-\theta^{*}, & c_{x}^{*}=-\beta^{*} \theta^{*} .
\end{aligned}
$$

Here $\theta$ and $\theta^{*}$ measure the effectiveness of each firm's R\&D in reducing its own costs; and $\beta$ and $\beta^{*}$ (which lie between 0 and 1) measure the extent to which R\&D has beneficial spillover effects on the rival firm's costs. The inverse demand function is given by

$$
p=p\left(q+q^{*}\right), \quad p^{\prime} \equiv-b, \quad\left(q+q^{*}\right) p^{\prime \prime} / p^{\prime} \equiv r,
$$

where $b$ is the slope of the demand function and $r$ is a measure of the concavity of demand. (Note we do not assume that any of the parameters $\theta$, $\theta^{*}, \beta, \beta^{*}, b$ or $r$, are constant.)

Summing costs and sales revenue and adding any export subsidy payments received (where $s$ is the per unit subsidy) gives the profits of the home firm:

\footnotetext{
${ }^{2} \mathrm{~A}$ longer version of the paper (giving the derivations in detail) and the GAUSS program which generates the figures, are available on request.
} 


$$
\pi=\left\{p\left(q+q^{*}\right)-c\left(x, x^{*}\right)+s\right\} q-\Gamma(x) .
$$

The foreign firm's profits $\pi^{*}$ are determined similarly, except that it receives no subsidies. Finally, with no home consumption, national welfare equals profits net of subsidy payments:

$$
W=\pi-s q=(p-c) q-\Gamma(x) .
$$

In all the games we consider, the two firms engage in Cournot productmarket competition in period 2 . Hence, with production costs determined by past decisions on $\mathrm{R} \& \mathrm{D}$, output levels are determined by the home and foreign firms' first-order conditions:

$$
\begin{aligned}
\pi_{q} & =p-c+s-b q=0 \\
\pi_{q^{*}}^{*} & =p-c^{*}-b q^{*}=0 .
\end{aligned}
$$

We consider four distinct games, in each of which the solution concept is subgame perfection (so at each stage, agents take account of how their current decisions affect the future decisions of all other agents). The games differ in whether or not firms cooperate in their choice of R\&D and whether or not the home government offers an export subsidy and can commit to it in advance of firms' $R \& D$ decisions:

(i) Game F: Free trade, with no cooperation on $R \& D$. In this benchmark two-stage game, firms choose R\&D levels in period 1 and outputs in period 2.

(ii) Game C: Free trade, with cooperation on $R \& D$. The move order is the same as in Game F. The difference is that firms cooperate in their choice of R\&D so as to maximise the sum of their joint profits. However, outputs in period 2 are still chosen in a non-cooperative Cournot-Nash manner. This game has been extensively examined in a closed-economy context, stemming from the work of d'Aspremont and Jacquemin (1988).

(iii) Game G: Government commitment to an export subsidy. In this threestage game, first studied by Spencer and Brander (1983), the government chooses the subsidy to maximise domestic welfare (4), setting $s$ before the firms' choice of both R\&D and exports.

(iv) Game S: Subsidisation without commitment. In this game the government also provides an export subsidy to maximise (4) but, unlike Game G, it cannot commit to the subsidy level before firms choose their R\&D levels. In this three-stage game, firms first choose their R\&D levels, then the government chooses its subsidy, and finally firms choose their output levels. This game has been considered by Karp and Perloff (1995), O'Sullivan (1995) and Grossman and Maggi (1998). 


\section{Strategic Investment with and without Cooperation on R\&D}

We consider first the two games where the home government does not intervene. In choosing its optimal level of $R \& D$, each firm takes account of the direct cost-reducing effect and also of the strategic effect of R\&D on its rival's output in the second stage. Thus, in Game F (the benchmark free-trade game with no cooperation on R\&D) the home firm's first-order condition for $\mathrm{R} \& \mathrm{D}$ is:

$$
\frac{\mathrm{d} \pi}{\mathrm{d} x}=\pi_{x}+\pi_{q^{*}} \frac{\mathrm{d} q^{*}}{\mathrm{~d} x}=0 .
$$

Here the direct or non-strategic effect of $\mathrm{R} \& \mathrm{D}, \pi_{x}$, equals $\theta q-\Gamma^{\prime}$, i.e., the gain from a reduction in the firm's production costs less the direct cost of the $R \& D$ itself. When this effect is zero, $R \& D$ is at its efficient level from the home country's perspective. Hence there is over- or under-investment in R\&D depending on whether the second term on the RHS is positive or negative. Since the home firm unambiguously gains from a fall in foreign output $\left(\pi_{q^{*}}=-b q<0\right)$, the sign of the second term depends on whether additional home $\mathrm{R} \& \mathrm{D}$ lowers or raises foreign output. This in turn depends on the following:

$$
b \frac{\mathrm{d} q^{*}}{\mathrm{~d} x}=-\alpha\left(\bar{\beta}-\beta^{*}\right) \theta^{*}, \quad \alpha>0, \quad \bar{\beta} \equiv \frac{\theta \pi_{q^{*} q}^{*}}{\theta^{*} \pi_{q q}},
$$

where the threshold parameter $\bar{\beta}$ is positive provided foreign output is a strategic substitute for domestic output (i.e., $\pi_{q^{*} q}^{*}<0$ ). (Strategic substitutability, equivalent to downward-sloping reaction functions, is the normal configuration in Cournot competition. We assume it holds henceforward.) Substituting into (6) we obtain:

$$
\frac{\mathrm{d} \pi}{\mathrm{d} x}=\mu^{\mathrm{F}} q-\Gamma^{\prime}=0, \quad \text { where } \quad \mu^{\mathrm{F}} \equiv\left[1+\alpha\left(\bar{\beta}-\beta^{*}\right)\right] \theta .
$$

$\mu^{\mathrm{F}}$ is the marginal return to R\&D per unit of output in free trade. ${ }^{3}$ Equations

\footnotetext{
${ }^{3}$ To derive (7), totally differentiate (5). The parameter $\alpha$ equals $-b \theta^{*} \pi_{q q} / \theta \Delta$ and must be positive since $\pi_{q q}<0$ from the home firm's second-order condition and $\Delta$, the determinant of the coefficient matrix, is positive from stability of the period-2 subgame. $\bar{\beta}$ can also be written as $\theta\left(1+\sigma^{*} r\right) / \theta^{*}(2+\sigma r)$, where $\sigma$ and $\sigma^{*}$ are the home and foreign market shares, respectively. This implies that $\bar{\beta}$ is greater than $\theta / 2 \theta^{*}$ if and only if $(2-3 \sigma) r>0$; i.e., if and only if either the home firm's market share is less than $\frac{2}{3}$ and demand is concave $(r>0)$, or the converse. In the linear symmetric case considered by d'Aspremont and Jacquemin (1988), $\theta^{*}=\theta, \sigma^{*}=\sigma=\frac{1}{2}$ and $r=0$, and so the threshold value equals $\frac{1}{2}$.
} 
(7) and (8) show that, with low spillovers $\left(\beta^{*}<\bar{\beta}\right)$, higher home R\&D lowers foreign output and so the home firm has an incentive to over-invest in $\mathrm{R} \& \mathrm{D}\left(\mu^{\mathrm{F}}>\theta\right)$. Conversely, with high spillovers $\left(\beta^{*}>\bar{\beta}\right)$, higher home $\mathrm{R} \& \mathrm{D}$ raises foreign output and so the home firm has an incentive to underinvest in $\mathrm{R} \& \mathrm{D}\left(\mu^{\mathrm{F}}<\theta\right)$. Since the foreign firm faces identical incentives, we may conclude that both firms invest more, the lower the spillover parameters $\beta$ and $\beta^{*}$.

The incentives to invest in $R \& D$ are very different in Game $C$ when cooperation by firms leads each of them to choose its $R \& D$ so as to maximise their joint profits. The home firm's first-order condition for R\&D is now:

$$
\frac{\mathrm{d}\left(\pi+\pi^{*}\right)}{\mathrm{d} x}=\left\{\pi_{x}+\pi_{q^{*}} \frac{\mathrm{d} q^{*}}{\mathrm{~d} x}\right\}+\left\{\pi_{x}^{*}+\pi_{q}^{*} \frac{\mathrm{d} q}{\mathrm{~d} x}\right\}=0 .
$$

This takes account of both direct and strategic effects on foreign as well as home profits. Similar calculations to those already given for the no-cooperation game show that:

$$
\frac{\mathrm{d}\left(\pi+\pi^{*}\right)}{\mathrm{d} x}=\mu^{\mathrm{C}} q-\Gamma^{\prime}=0, \quad \text { where } \quad \mu^{\mathrm{C}} \equiv \phi \theta+\phi^{\prime} \beta^{*} \theta^{*},
$$

and both $\phi$ and $\phi^{\prime}$ are presumptively positive. ${ }^{5}$ Now, the marginal return to $\mathrm{R} \& \mathrm{D}$ and hence the level of investment is typically increasing in the spillover parameter $\beta^{*}$. However, it is not true that cooperation fully internalises the externality arising from R\&D spillovers. Because of strategic behaviour the firm may either under- or over-invest in $\mathrm{R} \& \mathrm{D}$ from a national point of view. For low spillovers the final strategic term in (9), $\pi_{q}^{*} \mathrm{~d} q / \mathrm{d} x$, is negative and ensures that the firm under-invests in $\mathrm{R} \& \mathrm{D}\left(\mu^{\mathrm{C}}<\theta\right)$.

Will cooperation lead to more or less investment than non-cooperation? To answer this, we need only compare the two marginal return to $R \& D$ parameters, $\mu^{\mathrm{C}}$ and $\mu^{\mathrm{F}}$ :

\footnotetext{
${ }^{4}$ This and subsequent comparisons are exact with no further qualifications when the parameters $\theta, \beta$ and $\bar{\beta}$ are constants. More generally, the values of the two marginal returns to R\&D may differ between any two equilibria to be compared. From Leahy and Neary (1997, Section II.B), sufficient conditions to justify such comparisons are that equilibrium of each type is unique and that appropriate stability conditions hold.

${ }^{5}$ They equal: $\phi \equiv 1-\left\{\pi_{q^{*} q}^{*}-\left(\sigma^{*} / \sigma\right) \pi_{q^{*} q^{*}}^{*}\right\} b / \Delta=\left[2\left(2-3 \sigma^{*}\right)+\left\{1-2\left(\sigma^{*}\right)^{2}\right\} r\right] b^{2} / \sigma \Delta$ and $\phi^{\prime} \equiv \sigma^{*} / \sigma-\left\{\left(\sigma^{*} / \sigma\right) \pi_{q q^{*}}-\pi_{q q}\right\} \mathrm{b} / \Delta \stackrel{q^{*}}{=}\left[2(2-3 \sigma)+\left(1-2 \sigma^{2}\right) r\right] b^{2} / \sigma \Delta$. This implies that a sufficient condition for both $\phi>0$ and $\phi^{\prime}<\sigma^{*} / \sigma$ is that $\sigma \geqslant \frac{1}{2}$, while if demands are linear, a necessary and sufficient condition for these two outcomes is that $\sigma>\frac{1}{3}$. Symmetrically, a sufficient condition for both $\phi<1$ and $\phi^{\prime}>0$ is that $\sigma \leqslant \frac{1}{2}$, while if demands are linear, a necessary and sufficient condition for these two outcomes is that $\sigma<\frac{2}{3}$.
}

(C) The editors of the Scandinavian Journal of Economics 1999. 


$$
\mu^{\mathrm{C}}-\mu^{\mathrm{F}}=\alpha^{\prime}\left(\beta^{*}-\bar{\beta}^{\prime}\right) \theta^{*}, \quad \alpha^{\prime}>0, \quad \bar{\beta}^{\prime} \equiv \frac{\theta}{\theta^{*}} \frac{\pi_{q^{*} q^{*}}^{*}}{\pi_{q^{*} q^{*}}^{*}+2 \pi_{q q^{*}}} .
$$

Thus cooperation leads to more $\mathrm{R} \& \mathrm{D}$ if $\beta^{*}$ exceeds a new threshold, $\bar{\beta}^{\prime}$, which is positive provided domestic output is a strategic substitute for foreign output (i.e., $\pi_{q q^{*}}<0$ ). ${ }^{6}$

The final question to be addressed is whether cooperation raises welfare. Since we have assumed, following the strategic trade policy literature, that all output is exported, and since both Games $\mathrm{F}$ and $\mathrm{C}$ are free-trade equilibria, welfare and home profits coincide. ${ }^{7}$ Moreover, home profits must be at least as great with cooperation as without, since the aggregate profits of the two firms are maximised in the former case. Cooperation must lead to higher profits unless the two equilibria coincide, which occurs when the spillover parameter $\beta^{*}$ equals the threshold $\bar{\beta}^{\prime}$ given in (11).

\section{Export Subsidies with and without Government Commitment}

We turn next to equilibria with government intervention. In Game G, where the government can commit to its export subsidy prior to decisions on $R \& D$, the behaviour of firms is the same as in the non-cooperative free-trade game of the last section. Anticipating this behaviour, the government in the first stage chooses the export subsidy to maximise welfare, given by equation (4). To see the implications of this, totally differentiate (4):

$$
\mathrm{d} W=-s \mathrm{~d} q-b q \mathrm{~d} q^{*}+\left(\theta-\mu^{\mathrm{F}}\right) q \mathrm{~d} x+\beta \theta q \mathrm{~d} x^{*} .
$$

The first two terms on the RHS are standard. The first reflects the deadweight loss from increased exports when a subsidy is in place, while the second reflects the rent-shifting gain in welfare, as the foreign firm is pushed down its reaction function. The other two terms are less familiar. The term in $\mathrm{d} x$ reflects the divergence between marginal social and private returns to $R \& D$.

\footnotetext{
${ }^{6}$ As with (7), we make use of the fact that $\pi_{q^{*} q^{*}}^{*}<0$ from the foreign firm's second-order condition. $\alpha^{\prime}$ equals $-\left(\pi_{q^{*} q^{*}}^{*}+2 \pi_{q q^{*}}\right) \sigma b / \sigma^{*} \Delta$, which is positive. $\bar{\beta}^{\prime}$ can also be written as $\theta\left(2+\sigma^{*} r\right) / \theta^{*}[4+(1+\sigma) r]$, implying that $\bar{\beta}^{\prime}$ is greater than $\theta / 2 \theta^{*}$ if and only if $(1-3 \sigma) r>0$; i.e., if and only if either the home firm's market share is greater than $\frac{1}{3}$ and demand is concave $(r>0)$, or the converse. As with $\bar{\beta}$, the threshold value reduces to $\frac{1}{2}$ in the linear symmetric case.

${ }^{7}$ If instead we take a world welfare perspective, then the closed-economy results of Leahy and Neary (1997) apply. In particular, with low spillovers, the reduction in output brought about by $\mathrm{R} \& \mathrm{D}$ cooperation reduces consumer surplus to such an extent that total welfare (profits plus consumer surplus) is lower than without cooperation. Moreover, a cooperative typically underinvests in $\mathrm{R} \& \mathrm{D}$ for all $\beta^{*}$ : because of the strategic effects in (9), $\mu^{\mathrm{C}}$ is likely to be less than $\theta+\beta^{*} \theta^{*}$, which is the marginal world social return to domestic R\&D.
} 
When these differ, there is a motive for subsidisation to offset the inefficient investment which the home firm carries out for purely strategic reasons. Of course, this term can be either positive or negative: when spillovers are low, the home firm over-invests strategically so an offsetting tax is warranted, and conversely when spillovers are high. Finally, the fourth term reflects intertemporal rent-shifting, as opposed to the conventional intra-temporal kind represented by the second term. When spillovers are strictly positive, home profits and welfare are directly affected by foreign R\&D. Assuming (plausibly) that foreign $\mathrm{R} \& \mathrm{D}$ depends negatively on $s$, this term tends to encourage an export tax: government commitment to an export tax raises foreign $R \& D$ and so (because of spillovers) brings about a rise in profits that the home firm cannot credibly attain by itself.

While interpreting the terms in (12) is insightful, not much more can be said about their net impact on the sign of the optimal subsidy at this level of generality. The one thing we can be sure of is that the ability of the government to commit to an export subsidy must increase welfare relative to free trade. The situation is very different in Game S, when the government cannot commit to its subsidy level until after firms choose their R\&D. It therefore chooses the export subsidy to set to zero equation (12) without the R\&D terms. This leads to the static rent-shifting subsidy first derived by Brander and Spencer (1985):

$$
s\left(x, x^{*}\right)=-b q \frac{\mathrm{d} q^{*}}{\mathrm{~d} q},
$$

where $\mathrm{d} q^{*} / \mathrm{d} q$, the slope of the foreign firm's static reaction function, is negative provided foreign output is a strategic substitute for domestic output. We write the subsidy as a function of the two R\&D levels, because they are chosen prior to it. In the first stage of the game, both firms anticipate this dependence and take it into account in choosing their optimal R\&D levels. Thus the first-order condition for home R\&D is now:

$$
\frac{\mathrm{d} \pi}{\mathrm{d} x}=\pi_{x}+\pi_{q^{*}} \frac{\mathrm{d} q^{*}}{\mathrm{~d} x}+\pi_{s} \frac{\partial s}{\partial x}=0 .
$$

A higher subsidy must raise profits $\left(\pi_{s}=q>0\right)$, so the impact of the additional final term on the marginal profitability of $R \& D$ hinges on the effect of R\&D on the optimal subsidy, $\partial s / \partial x$. Leahy and Neary (1999b) derive a necessary and sufficient condition for this term to be positive and show that this is the normal case. ${ }^{8}$ Assuming for concreteness that this is so,

\footnotetext{
${ }^{8}$ Over-strong sufficient conditions for $\partial s / \partial x$ to be positive are that both the demand curve and the foreign reaction function are non-convex. These conditions are satisfied if demand is linear, as in Section VI below.
}

(C) The editors of the Scandinavian Journal of Economics 1999. 
the home firm over-invests further in R\&D. It does so both because $R \& D$ directly raises the subsidy it will receive (as shown by the third term in (14)) but also because a positive value for $\partial s / \partial x$ indirectly raises the effectiveness of home R\&D in lowering foreign output. ${ }^{9}$ Finally, the foreign firm faces a similar incentive. Its first-order condition is:

$$
\frac{d \pi^{*}}{\mathrm{~d} x^{*}}=\pi_{x^{*}}^{*}+\pi_{q}^{*} \frac{\mathrm{d} q}{\mathrm{~d} x^{*}}=0 .
$$

Foreign profits are not affected directly by changes in the home subsidy. However, the magnitude of $\mathrm{d} q / \mathrm{d} x^{*}$ depends on the responsiveness of the subsidy to foreign R\&D, $\partial s / \partial x^{*}$. Just as we would expect higher home $R \& D$ to mandate a higher subsidy, so would we expect higher foreign $R \& D$ to mandate a lower subsidy. This in turn makes it more likely that $\mathrm{d} q / \mathrm{d} x^{*}$ will be negative and so encourages over-investment by the foreign firm too.

What is the effect on welfare of these additional incentives to engage in $\mathrm{R} \& \mathrm{D}$ which both firms face as a result of the endogeneity of the subsidy? In general, we can be sure that in this model the government's inability to commit cannot raise welfare relative to the commitment game and will lower it if $R \& D$ has any effect on costs. We can say something further by inspection of (12). The third term (substituting from (14) for the marginal return to $\mathrm{R} \& \mathrm{D}$ in this game) shows that extra investment by the home firm lowers welfare except when spillovers are high. As for extra investment by the foreign firm, it has a direct effect tending to raise welfare, provided there are positive spillovers. However, it also has an indirect effect on the location of the foreign firm's period-2 reaction function. This effect tends to increase foreign output and is not offset by the subsidy (which, from (13), only neutralises the effects of foreign output changes along a given foreign reaction function). Except for high spillovers this effect is likely to dominate, thereby reducing home welfare further.

\section{Comparing Welfare across Equilibria}

The welfare results of the two previous sections may be summarised as follows:

$$
W^{C} \geqslant W^{F}<W^{G} \geqslant W^{S} .
$$

From Section III, cooperation cannot lower welfare relative to free trade and

\footnotetext{
${ }^{9}$ When $s$ depends on $x$, the threshold parameter $\bar{\beta}$ in (7) becomes $(\theta+\partial s / \partial x) \pi_{q^{*} q}^{*} / \theta^{*} \pi_{q q}$. Thus a positive value for $\partial s / \partial x$ makes $\mathrm{d} q^{*} / \mathrm{d} x$ more likely to be negative and increases further the incentive to invest in $\mathrm{R} \& \mathrm{D}$.
} 
will raise it except when the spillover parameter $\beta^{*}$ equals the threshold value $\bar{\beta}^{\prime}$ given in equation (11). From Section IV, commitment to an optimal export subsidy always raises welfare relative to free trade; and it raises welfare relative to an optimal subsidy without commitment except when $\mathrm{R} \& \mathrm{D}$ is ineffective (when the commitment issue is irrelevant).

These results are interesting but they leave open two crucial questions. First, when will intervention without commitment raise welfare relative to free trade? Clearly, if R\&D is ineffective, there is no cost to the government's inability to commit $\left(W^{\mathrm{G}}=W^{\mathrm{S}}\right)$ and so $W^{\mathrm{S}}$ exceeds $W^{\mathrm{F}}$. However, when R\&D is effective then, as Karp and Perloff (1995), O'Sullivan (1995) and Grossman and Maggi (1998) have shown, over-investment by the home firm with a view to manipulating the export subsidy can lower welfare relative to free trade. Second, as posed in the paper's title, when will optimal intervention raise welfare relative to international $R \& D$ cooperation? This in turn implies two sub-questions, since intervention may be with or without commitment. We can infer from (16) that intervention with commitment dominates cooperation when $\beta^{*}$ equals the threshold given in equation (11). Moreover, intervention without commitment dominates cooperation when $R \& D$ is ineffective.

\section{The Linear-Quadratic Case}

To go beyond the weak sufficient conditions discussed in the last section, we simplify the model by assuming that firms are symmetric and that the behavioural functions take special forms. ${ }^{10}$ Specifically, we assume that the demand function is linear:

$$
p\left(q+q^{*}\right)=a-b\left(q+q^{*}\right)
$$

that each firm's marginal production cost function is linear in its own and its rival's $R \& D$ :

$$
c\left(x, x^{*}\right)=c_{0}-\theta\left(x+\beta x^{*}\right) \quad \text { and } \quad c^{*}\left(x^{*}, x\right)=c_{0}-\theta\left(x^{*}+\beta x\right) ;
$$

and that the $R \& D$ cost functions are quadratic in $R \& D$ :

$$
\Gamma(x)=\gamma x^{2} / 2 \text { and } \Gamma^{*}\left(x^{*}\right)=\gamma\left(x^{*}\right)^{2} / 2 .
$$

(All the parameters $a, b, c_{0}, \theta, \beta$ and $\gamma$ are constant.) Fortunately, comparisons between the four games with symmetry depend on only two parameters:

\footnotetext{
${ }^{10}$ Asymmetries between firms in similar linear-quadratic models, but without spillovers, are considered in Neary (1994), Karp and Perloff (1995) and Leahy and Neary (1999b).
}

(C) The editors of the Scandinavian Journal of Economics 1999. 
the degree of spillovers $\beta$ and a new composite parameter $\eta$, defined as $\eta \equiv \theta^{2} / b \gamma$. Following Leahy and Neary (1996), this can be interpreted as the relative effectiveness of $R \& D$, since $\theta$ gives the reduction in unit production costs per unit of R\&D, $\gamma$ is the marginal cost of $\mathrm{R} \& \mathrm{D}$ and $b$ (the slope of the demand function) is a measure of the size of the market. Figures 1 to 5 compare the levels of welfare in each of the four games as functions of $\eta$ and $\beta$ (with the normalisation $\left(a-c_{0}\right)^{2}=9 b$, so that welfare in free trade is unity when $\eta$ is zero).

Figure 1 shows that welfare in free trade falls with $\eta$ in the absence of spillovers, as additional strategic over-production benefits consumers at the expense of firms. ${ }^{11}$ However, welfare rises with $\eta$ for moderate or high

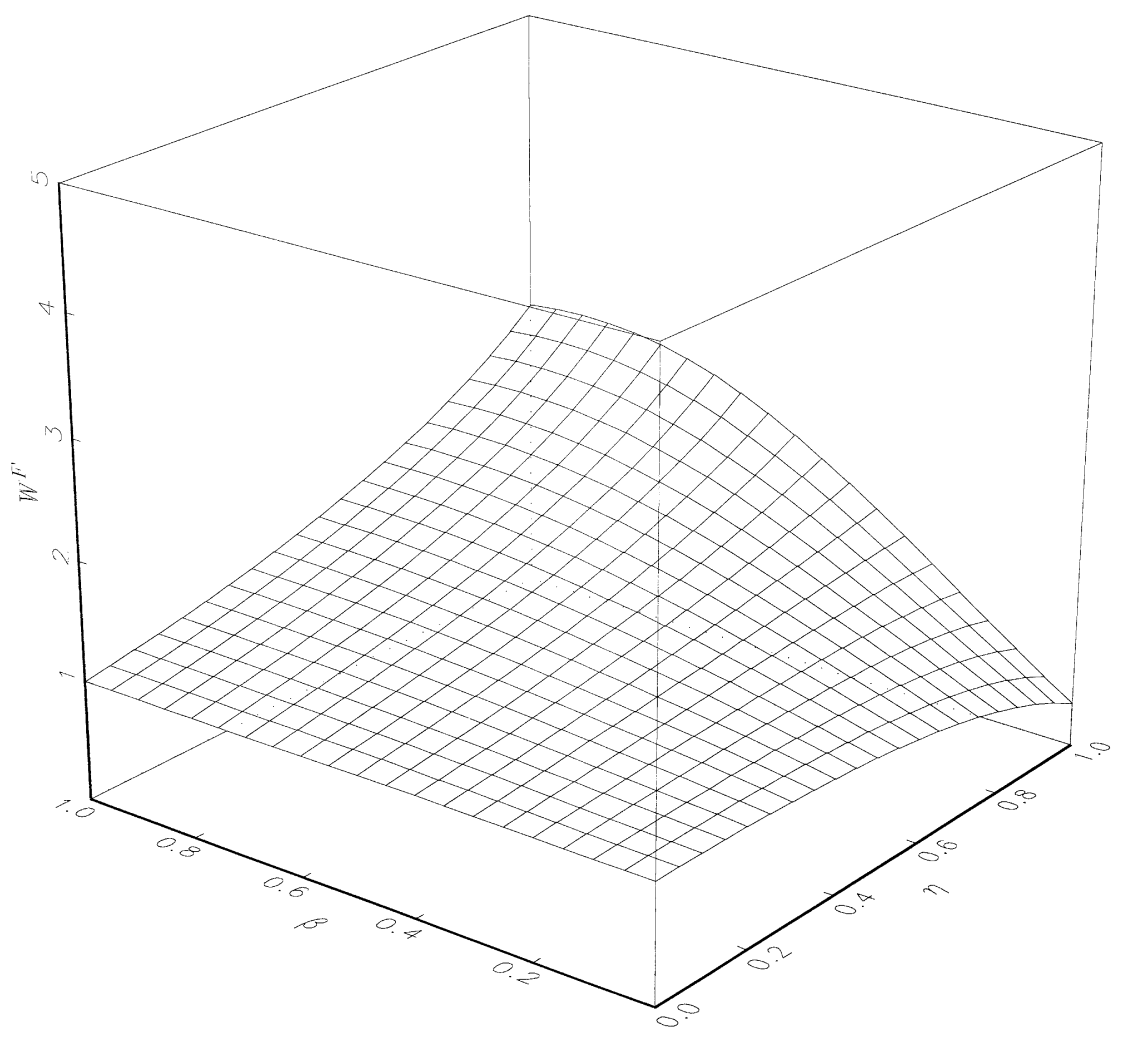

Fig. 1. Welfare in free trade

${ }^{11}$ This was also noted in Leahy and Neary (1996, footnote 6$)$. The explicit solutions are:

$$
W^{\mathrm{F}}=\frac{9-2(2-\beta)^{2} \eta}{[9-2(1+\beta)(2-\beta) \eta]^{2}} \quad \text { and } \quad W^{\mathrm{C}}=\frac{1}{9-2(1+\beta)^{2} \eta} .
$$


spillovers and (provided $\eta$ is strictly positive) always rises with $\beta$. (Though recall from Section III that with higher spillovers firms engage in less R\&D.) Compare this with the level of welfare when firms cooperate on R\&D, shown in Figure 2. Now welfare rises with $\eta$ even with no spillovers. (Of course, in this case, cooperation has no cost-saving implication and is purely a strategic device which avoids over-investment and so leads to less R\&D.) Welfare rises even more rapidly when both parameters attain moderate or high levels, reaching a value of 9.0 (truncated from the figure to facilitate presentation) when both $\eta$ and $\beta$ are unity.

We know from Section III that cooperation always raises welfare, except when $\beta$ attains its threshold level $\bar{\beta}$ (equal to $\frac{1}{2}$ with linear demands). Comparison of Figures 1 and 2 shows in addition that the gains from cooperation are increasing in $\eta$ and in the absolute gap between $\beta$ and $\frac{1}{2}$. Recall, however, that cooperation is preferable for very different reasons in the low- and high-spillover cases. For low $\beta$, it allows the firms to reduce

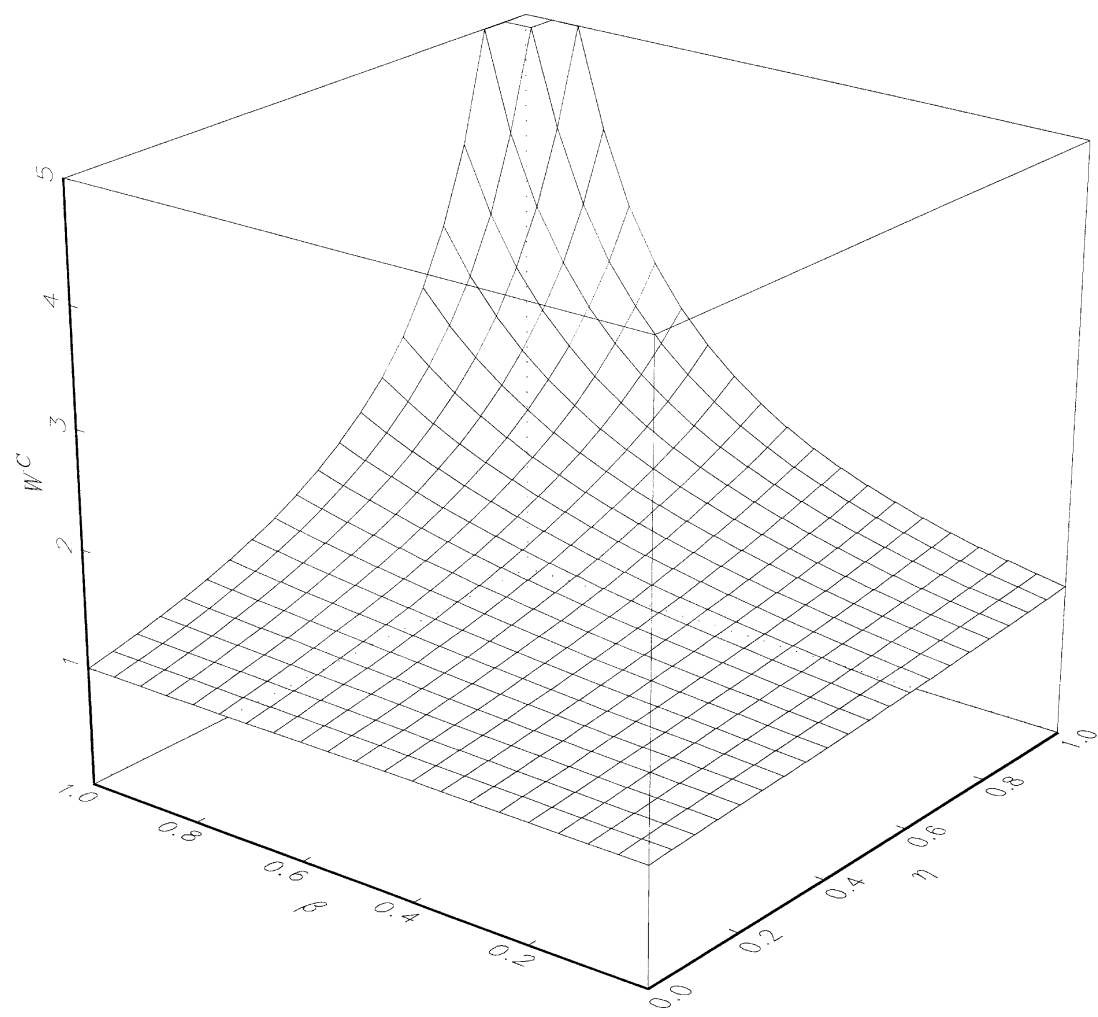

Fig. 2. Welfare with cooperation on $\mathrm{R} \& \mathrm{D}$

(C) The editors of the Scandinavian Journal of Economics 1999. 
their R\&D and avoid strategic over-investment; whereas for high $\beta$ it has the more natural effect of increasing $R \& D$, though still not to the efficient level (from a world perspective).

Turning next to the two cases where the government intervenes to provide an export subsidy ( $G$ and $S$ ), a complication arises. If $R \& D$ is even moderately effective, the effect of the subsidy may be to drive the foreign firm from the market. For parameter values at which this happens, we assume that the home government offers a subsidy just sufficient to drive foreign profits to zero. In Game G, the government commits in advance of $\mathrm{R} \& \mathrm{D}$ decisions to the entry-preventing subsidy. Moreover, for some parameter values an optimal rent-shifting equilibrium may exist, in which the foreign firm earns strictly positive profits, and yet entry prevention yields higher welfare. The reason is that, with entry prevention, home investment in $\mathrm{R} \& \mathrm{D}$ is always at the efficient level (defined by $\theta q=\Gamma^{\prime}$ ), since, if the foreign firm does not enter, the home firm has no strategic incentive to overinvest.

The outcome of these considerations is the welfare function for Game $\mathrm{G}$ shown in Figure 3. It is clearly the upper envelope of two single-peaked functions. ${ }^{12}$ That covering the larger part of the parameter space corresponds to the rent-shifting equilibrium. It starts at $1.125(=9 / 8)$ when there is no $\mathrm{R} \& \mathrm{D}$ and increases relatively gently in both $\eta$ and $\beta$ thereafter. The other function corresponds to the entry-prevention equilibrium. It applies when $R \& D$ is relatively effective (so subsidisation causes the home firm to expand a lot and squeeze out foreign output) and spillovers are low (so the foreign firm does not benefit from home R\&D). It is clearly strongly increasing in $\eta$ and decreasing in $\beta$.

We know from general principles that the welfare level attainable when the government commits to a subsidy must exceed that in free trade. However, comparing Figures 1 and 3, it is striking that the gains from an optimal rent-shifting subsidy are relatively modest: $12.5 \%$ in the static case when $\eta$ is zero, as we have seen, and even less when both $\eta$ and $\beta$ are high. By contrast, the gains from entry prevention (when $\eta$ is high and $\beta$ is low) are considerable. Figure 4 shows that entry prevention also leads to large gains relative to cooperation. However, with rent shifting the gains are much smaller and, when spillovers are high and $R \& D$ very effective, rent-shifting is inferior to cooperation. This figure provides one answer to the question posed in the title of the paper. Commitment dominates cooperation for most parameter values, though only modestly except when it enables the home government to deter entry by the foreign firm.

\footnotetext{
${ }^{12}$ The welfare level with rent shifting is too complex to evaluate explicitly. It is obtained by substituting the optimal subsidy from footnote 15 below into the with-subsidy welfare function $W=(b q-s) q-\gamma x^{2} / 2$. Welfare with entry prevention equals $(1-2 \beta) \eta / 2(1-\beta \eta)^{2}$.
} 


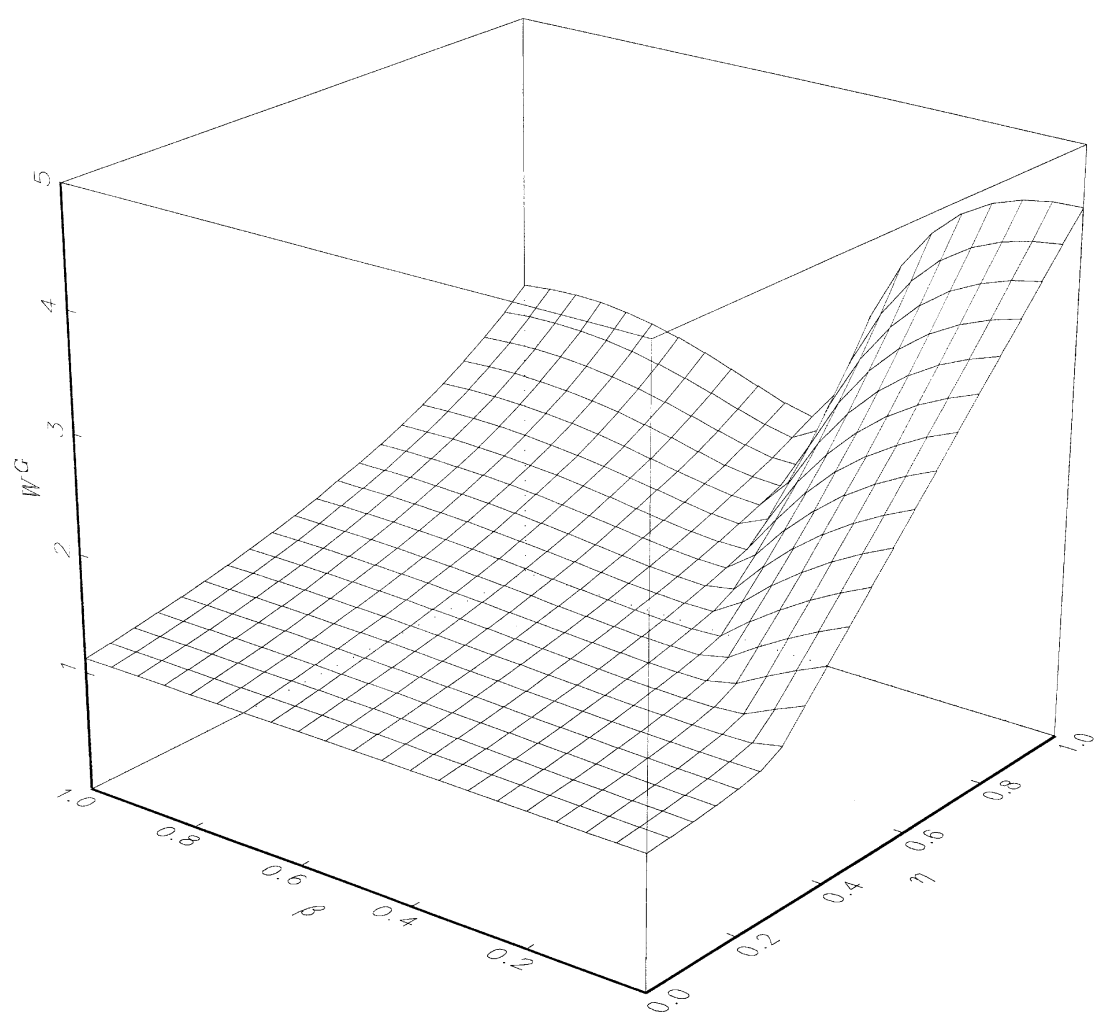

Fig. 3. Welfare with government commitment

Of course, the assumption that the government can commit in advance to its export subsidy prejudices the comparison against cooperation. The story is very different when the government cannot commit to its subsidy, as illustrated in Figure 5. Once again, there is both a rent-shifting and an entryprevention regime. However, since the government moves second, it is effectively the home firm which determines which regime prevails. ${ }^{13}$ As in Game $\mathrm{G}$, the rent-shifting regime prevails over most of the parameter space.

\footnotetext{
${ }^{13}$ In the entry-prevention case, the home firm chooses a level of investment just sufficient to induce a subsidy that drives the foreign firm's profits to zero. This does not mean that the home firm is actually a Stackelberg leader, although (just as in the Brander-Spencer game) the outcome is the one it would choose if it were. In the first stage of the game, the entrypreventing level of investment by the home firm and a zero level by the foreign firm are best responses to each other. Welfare in the rent-shifting and entry-prevention regimes equals $W^{\mathrm{S}}=\left[1-(2-\beta)^{2} \eta\right] b\left(q^{\mathrm{S}}\right)^{2} / 2$ and $\bar{W}^{\mathrm{S}}=\left[4(1-\beta)^{2} \eta-1\right] / 2(2-3 \beta)^{2} \eta$, respectively.

(C) The editors of the Scandinavian Journal of Economics 1999.
} 


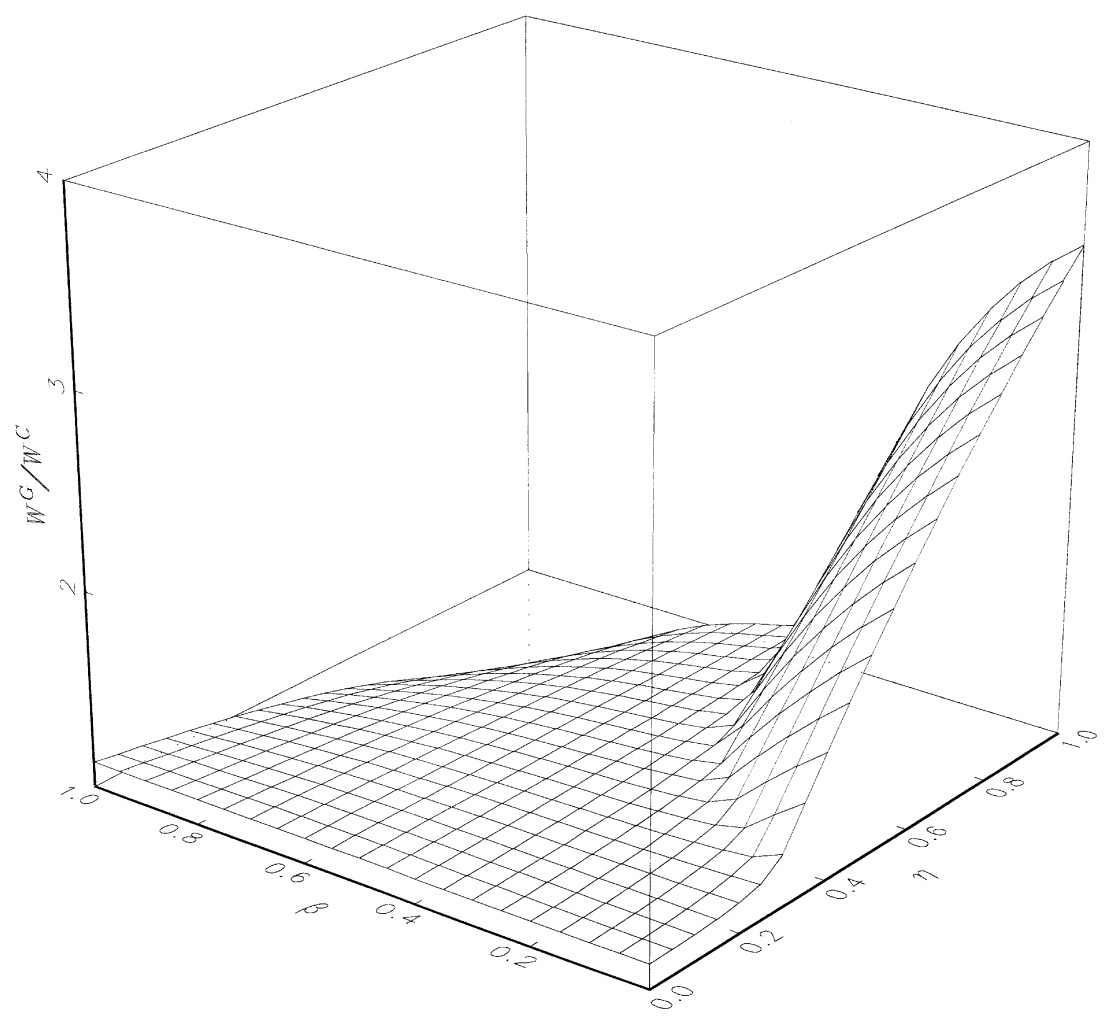

Fig. 4. Welfare with commitment relative to cooperation

Welfare is lower the more effective is R\&D, though it falls less rapidly for higher spillovers. This contrasts sharply with the entry-prevention regime, which as in Game $\mathrm{G}$ is the dominant policy when $\mathrm{R} \& \mathrm{D}$ is highly effective and spillovers are low. Welfare now increases rapidly in $\eta$ and declines rapidly in $\beta .{ }^{14}$ Note that there is a wide range of parameters (high $\eta$ and intermediate to high $\beta$ ) for which welfare is negative, often highly so. (Of course, home profits are always positive.) Comparing Figure 5 with Figures 1 and 2, the rent-shifting regime in Game S yields higher welfare than either free trade or cooperation only for low values of $\eta$, although if entry prevention occurs, Game S may yield considerably higher welfare.

\footnotetext{
${ }^{14}$ With no spillovers, the no-commitment case dominates free trade for low and high values of $\eta$ but not for intermediate values: a U-shape also found by Grossman and Maggi (1998) but for different reasons. In their model, only the home firm invests in R\&D and when $\eta$ is high, the extra subsidy-induced investment has a low social cost. In our symmetric model, the U-shape reflects the higher welfare attainable with entry prevention when $\eta$ is high.
} 


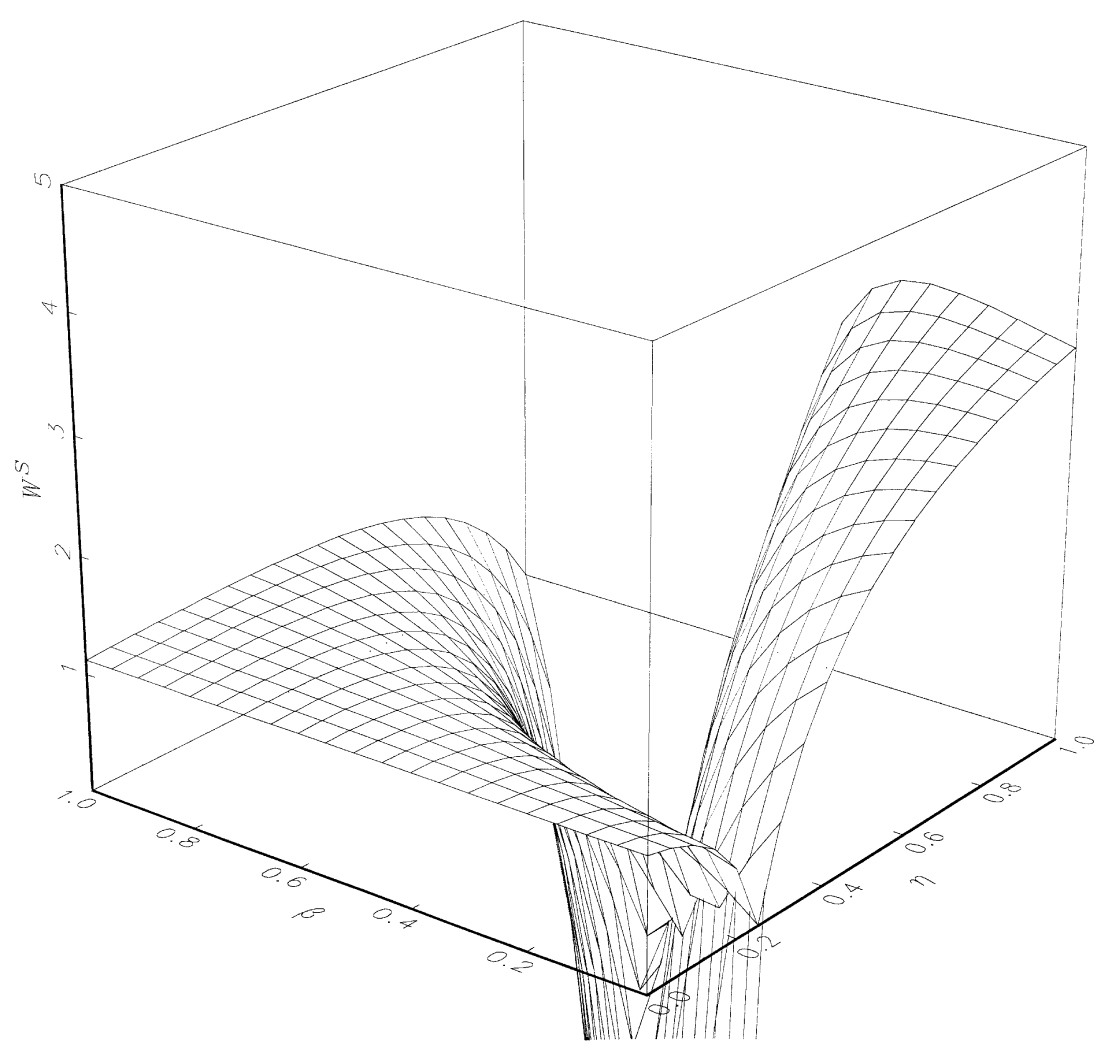

Fig. 5. Welfare without government commitment

The last issue we address is the size of the subsidies in the $G$ and $S$ equilibria, shown in Figures 6 and 7, respectively. The relatively flat portion of Figure 6 corresponds to the optimal rent-shifting subsidy in Game G. Although the vertical scale masks its variation, it is a complicated function of $\eta$ and $\beta$, reflecting the interaction of the different motives for subsidisation implied by (12).$^{15}$ However, all this variation is dwarfed by the contrast with, first, the entry-prevention subsidy in Game G, which is typically much larger and is strongly decreasing in both $\eta$ and $\beta$; and, second, the optimal subsidy in both regimes of Game S shown in Figure 7. (Once again, extreme values

${ }^{15}$ The optimal rent-shifting and entry-prevention subsidies in Game $\mathrm{G}$ are:

$$
s^{\mathrm{G}}=\left\{\frac{\left[1-\frac{2}{3} \beta(2-\beta) \eta\right]^{2}}{2\left[1-\frac{1}{3}(2-\beta) \eta\right]}-\frac{2}{9}(1-2 \beta)(2-\beta) \eta\right\} b q^{\mathrm{G}}, \quad \bar{s}^{\mathrm{G}}=\frac{1-(1-\beta) \eta}{1-\beta \eta}\left(a-c_{0}\right) .
$$




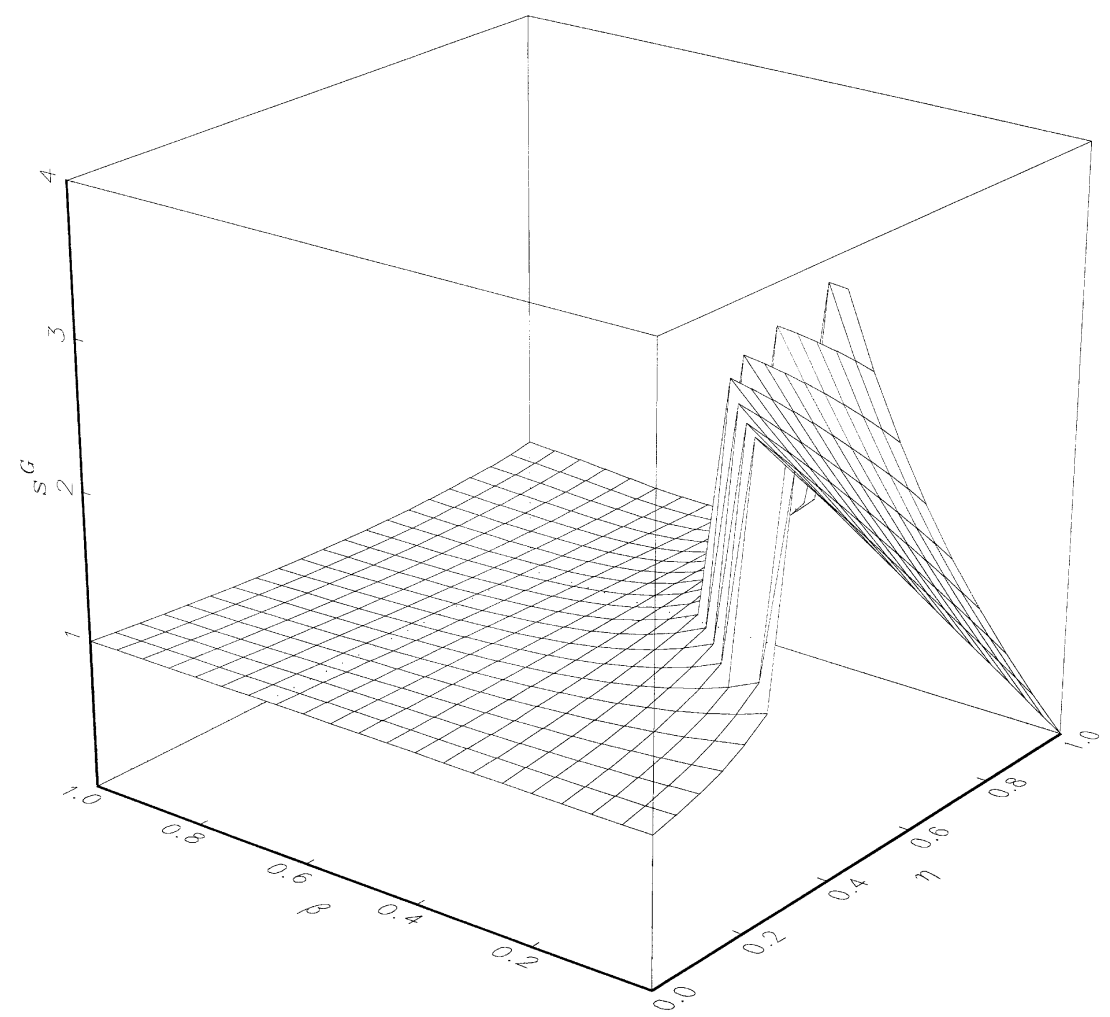

Fig. 6. Optimal subsidy with commitment

of the optimal subsidy have been truncated to facilitate viewing the figure.) For all positive values of $\eta$ the optimal subsidy without commitment is considerably greater than the corresponding subsidy with commitment. This suggests that a simple device to avoid the welfare losses from an inability to commit would be to place a ceiling on the subsidy rate or on the total amount of subsidy payments.

\section{Conclusion}

In this paper we have compared adversarial with cooperative industrial and trade policies in a dynamic oligopoly game where a home and a foreign firm compete in R\&D and output and, because of spillovers, each benefits from the other's $R \& D$. We have shown that the choice between subsidising exports and facilitating international research joint ventures depends on three key features: the effectiveness of $R \& D$ in reducing costs, the extent of spillovers 


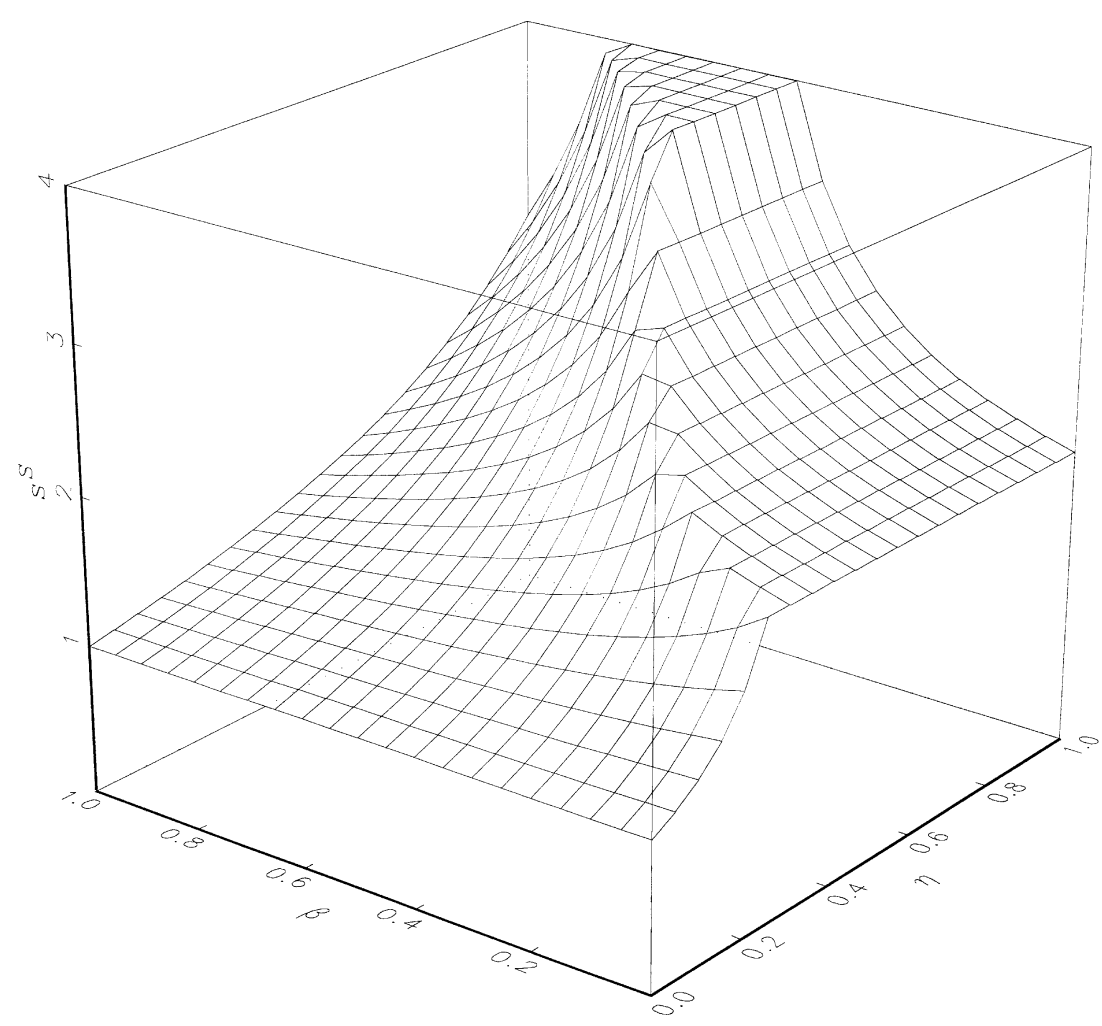

Fig. 7. Optimal subsidy without commitment

between firms, and whether or not the government can commit to an export subsidy in advance of firms' investment decisions.

Concerning $R \& D$ cooperation, we show that it raises profits and hence (ignoring home consumption) raises domestic welfare for either high or low spillovers. However, the reasons it does so differ between the two cases. With low spillovers, each firm has an incentive to over-invest to give itself a strategic advantage against its rival in subsequent product-market competition. Cooperation over-internalises this externality, serving in effect as an anti-competitive device to restrict $R \& D$ and output, so world welfare falls even as national welfare rises. By contrast, with high spillovers, each firm faces an incentive to under-invest, since otherwise its rival will enjoy the benefits of its cost-reducing investments. Cooperation again raises national welfare but it leads to over-investment from a national point of view, to the benefit of foreign consumers.

As for an export subsidy, it typically yields modest welfare gains relative 
to $R \& D$ cooperation, provided the government can commit before $R \& D$ decisions are taken. Figure 4 highlights two exceptions to this generalisation. First, if $R \& D$ is very effective and spillovers are near-complete, $R \& D$ cooperation is sure to raise welfare much more than subsidisation. Second, if $R \& D$ is very effective but spillovers are low, the optimal policy is a subsidy sufficiently high to prevent the foreign firm from entering the market. In such cases, the welfare gains from exploiting a monopoly position where R\&D greatly reduces costs exceed the benefits from cooperation. Of course, such a policy would be vulnerable to pressures from international regulatory bodies and to retaliation by foreign governments. Nevertheless the scale of the potential welfare gains highlights the incentives which governments face to engage in such predatory policies. The answer to the question posed in the title of this paper is therefore that "beat 'em" is mildly better than "join 'em" but, if you can get away with it, "kill 'em" is best of all!

A key determinant of our results is the size of the spillover parameter $\beta$. Empirical evidence, reviewed by Griliches (1992), suggests a relatively low value of between 0.2 and 0.4 , implying that adversarial strategies are likely to be preferable to cooperative ones. On the other hand, many authors have suggested that $\beta$ should be viewed as a choice variable. Kamien et al. (1992) go further and argue that information sharing will always ensure that spillovers are complete $(\beta=1)$ when cooperation occurs. Which of these arguments dominates presumably depends on the particular industry to which the model is applied. However, in all cases the caveat noted in Leahy and Neary (1997) should be borne in mind: cooperation always raises profits relative to non-cooperation, so the relevant issue for policy is whether cooperation should be prohibited rather than whether it should be encouraged.

The final issue which our results address is the likelihood and size of the welfare losses from strategic trade policy when the government cannot commit to its subsidy before firms' investment decisions. Our simulations show that the welfare losses from the resulting socially wasteful strategic investments may indeed be substantial. However, they also point to two qualifications to this argument. First, if $R \& D$ is relatively effective and spillovers are low, the home firm may be able to engage in a level of investment which prevents the foreign firm from entering the market. The surprising feature of this outcome is not that the existence of a strategic trade policy programme leads to a monopoly position for the home firm even when both firms are ex ante identical. Rather it is that the resulting monopoly profits may raise welfare above the level it would have reached even with R\&D cooperation. Second, whether the foreign firm enters or not, the resulting optimal subsidy is many times greater than it would be if there was no $R \& D$ and/or if the government could commit in advance. This suggests that capping the level of subsidy payments may be a simple but 
effective way of avoiding the capture of subsidy programmes by domestic firms.

\section{References}

Brander, J. A. (1995), Strategic Trade Policy, in G. Grossman and K. Rogoff (eds.), Handbook of International Economics, Vol. III, North-Holland, Amsterdam, 13951455.

Brander, J. A. and Spencer, B. J. (1985), Export Subsidies and International Market Share Rivalry, Journal of International Economics 18, 83-100.

d'Aspremont, C. and Jacquemin, A. (1988), Cooperative and Noncooperative R\&D in Duopoly with Spillovers, American Economic Review 78, 1133-1137.

Goldberg, P. (1995), Strategic Export Promotion in the Absence of Government Commitment, International Economic Review 36, 407-426.

Griliches, Z. (1992), The Search for R\&D Spillovers, Scandinavian Journal of Economics 94, S29-S47.

Grossman, G. and Maggi, G. (1998), Free Trade vs. Strategic Trade: A Peek into Pandora's Box, in R. Sato, R.V. Ramachandran and K. Mino (eds.): Global Integration and Competition, Kluwer Academic Publishers, Dordrecht.

Guffens, D. (1995), Strategic R\&D Policy in the Presence of Spillovers, mimeo, London School of Economics.

Kamien, M. I., Muller, E. and Zang, I. (1992), Research Joint Ventures and R\&D Cartels, American Economic Review 82, 1293-1306.

Karp, L. S. and Perloff, J. M. (1995), The Failure of Strategic Industrial Policies due to Manipulation by Firms, International Review of Economics and Finance 4, 1-16.

Leahy, D. and Neary, J. P. (1996), International R\&D Rivalry and Industrial Strategy without Government Commitment, Review of International Economics 4, 322-338.

Leahy, D. and Neary, J. P. (1997), Public Policy towards R\&D in Oligopolistic Industries, American Economic Review 87, 642-662.

Leahy, D. and Neary, J. P. (1999a), R\&D Spillovers and the Case for Industrial Policy in an Open Economy, Oxford Economic Papers 51, 40-59.

Leahy, D. and Neary, J. P. (1999b), Learning by Doing, Precommitment and Infant Industry Promotion, Review of Economic Studies 66, 447-474.

Maskin, E. and Newbery, D. (1990), Disadvantageous Oil Tariffs and Dynamic Consistency, American Economic Review 80, 143-156.

Motta, M. (1996), Research Joint Ventures in an International Economy, Ricerche Economiche 50, 293-315.

Muniagurria, M. E. and Singh, N. (1997), Foreign Technology, Spillovers and R\&D Policy, International Economic Review 38, 405-430.

Neary, J. P. (1994), Cost Asymmetries in International Subsidy Games: Should Governments Help Winners or Losers?, Journal of International Economics 37, 197-218.

O'Sullivan, P. (1995), Optimal Export Subsidies in an Oligopolistic Industry given R\&D Spillovers, M.A. Thesis, University College Dublin.

Qiu, L. D. and Tao, Z. (1998), Policy on International R\&D Cooperation: Subsidy or Tax?, European Economic Review 42, 1727-1750.

Spencer, B. J. and Brander, J. A. (1983), International R\&D Rivalry and Industrial Strategy, Review of Economic Studies 50, 707-722. 